\title{
Exegese sobre a constitucionalidade da administração judicial em conflitos societários*
}

\author{
Marcelo Lauar Leite** \\ Recibido: mayo de 2015 \\ Evaluado: agosto de 2015 \\ Aprobado: noviembre de 2015
}

\section{RESUMO}

Trata-se de artigo que, pautado no direito à liberdade de iniciativa, debate a constitucionalidade da medida judicial que determina a intervenção em sociedades empresárias em conflito por meio de terceiros na qualidade de administradores provisórios. Para tanto, adotou-se o método hipotético-dedutivo de abordagem, iniciando-se com a categorização da livre iniciativa como um direito fundamental. Em seguida, é traçado o panorama das citadas medidas judiciais nominativas. Mais que buscar e oferecer uma simples resposta, são traçadas métricas de constitucionalidade calcadas em argumentos sediados na teoria dos direitos fundamentais e no direito societário. Como principal resultado, viu-se que, ainda que se dê com a nomeação de terceiros para a função de gestor mercantil, a intervenção judicial em conflitos societários preserva o núcleo essencial da livre iniciativa, bem como os interesses sociais e extra-sociais que circundam a organização empresarial, configurando-se, abstratamente, como medida legítima e constitucional.

Palavras-chave: Liberdade de iniciativa, Sociedades comerciais, Conflito entre sócios, Administradores Judiciais, Constitucionalidade.

\footnotetext{
Este artigo é fruto de investigação de doutoramento em Ciências Jurídicas-Empresariais na Faculdade de Direito da Universidade de Coimbra, intitulada "Parâmetros interventivos para a nomeação e atuação de Administradores Judiciais em Sociedades Limitadas", a qual se encontra e andamento e tem, neste Autor, o único e principal pesquisador, orientado pelo Professor Doutor Pedro Canastra de Azevedo Maia.

** Advogado e Professor Assistente da Universidade Federal Rural do Semi-Árido (UFERSA). Bacharel e Mestre em Direito pela Universidade Federal do Rio Grande do Norte (UFRN). Doutorando em Ciências JurídicoEmpresariais pela Universidade de Coimbra. E-mail: marcelolauar@yahoo.com.br
} 


\title{
La exégesis sobre la constitucionalidad de la administración judicial en conflictos societarios
}

\begin{abstract}
RESUMEN
En este artículo, basado en el derecho a la libertad de iniciativa, se discute la constitucionalidad de la medida judicial que determina la intervención en sociedades comerciales en conflicto mediante administradores judiciales provisionales. Por lo tanto, se eligió el método hipotético-deductivo de enfoque, comenzando con la clasificación de la libre empresa como un derecho fundamental. Posteriormente, se presenta el panorama de las medidas judiciales dichas. Más que buscar y proporcionar una respuesta simple, se diseñan métricas de constitucionalidad basadas en argumentos que se encuentran en la teoría de los derechos fundamentales y en el derecho de sociedades. Como resultado principal, se vio que, incluso si toman la designación de terceros a la función de gestor comercial, la intervención judicial en conflictos societarios conserva el núcleo esencial de la libre empresa y los intereses corporativos y extra-sociales que rodea la organización empresarial, estableciendose de forma abstracta, como una medida legítima y constitucional.
\end{abstract}

Palabras clave: Libertad de iniciativa, Sociedades comerciales, Conflicto entre los sócios, Administradores judiciales, Constitucionalidad.

\section{Exegesis on the constitutionality of the provisional custodians in corporate conflicts}

\begin{abstract}
For this article, based on the right to freedom of initiative, is discussed the constitutionality of judicial measure that determines the intervention in business corporations in conflict through provisional custodians. For this, it was chosen the hypothetical-deductive method of approach, starting with the categorization of free enterprise as a fundamental right. Subsequently, the panorama of the said judicial measures is presented. More than seek and provide a simple answer, are drawn constitutionality metric modeled on arguments based on the theory of fundamental rights and corporate law. As a main result, it was seen that, even if judicial intervention happen to the appointment of third parties for commercial administrator role, it preserves the essential nucleus of free enterprise and the social and extra-social corporate interests that surround the business organization, performing, abstractly, as a legitimate and constitutional measure.
\end{abstract}

Key words: Freedom of initiative, Business corporations, Conflict between partners, Provisional custodians, Constitutionality. 


\section{INTRODUCÃO}

Nas palavras de Otacílio Silveira Neto (2013, p. 126), não há, sobre a terra, nenhuma força que impulsione o homem para o desenvolvimento de forma tão expressiva quanto a liberdade. Apesar das frequentes e justificadas remessas aos ideais presentes no seio da Revolução Francesa, a liberdade é um valor ontológico do ser humano, não tendo naquele marco histórico, propriamente, o seu nascimento. Trata-se, filosoficamente, como disse Eros Grau (2014), da sensibilidade e acessibilidade a alternativas de conduta $e$ de resultado. Quer-se, com isso, dizer que não se pode entender como livre aquele que nem mesmo sabe de sua possibilidade de reivindicar alternativas de conduta e comportamento (sensibilidade); e não se pode chamar de livre, também, aquele ao qual tal acesso é sonegado (acessibilidade) (Grau, 2014, p. 199)'.

De ordem dessa reflexão, no campo semântico, é recorrente a significação da liberdade como o grau de independência legítimo que um cidadão ou povo de uma nação elege como valor supremo, como ideal (Dicionário Houaiss da Língua Portuguesa, 2009, p. 1.175) ou a faculdade de uma pessoa fazer ou deixar de fazer alguma coisa por sua vontade (Grande Dicionário da Língua Portuguesa: E-N, 1972, p. 1.600). Tais acepções, transportadas para a seara jurídica, apresentam contornos semelhantes, porém, acrescidos de aspectos legais, como a relevância da sua garantia contra

No mesmo sentido, Cf. Alexy, 2008, p. 222. [(...) só se falará em liberdade jurídica quando o objeto da liberdade for uma alternativa de ação.] a arbitrariedade (Black's Law Dictionary, 2009, p. 1.001) oriunda de fontes públicas ou privadas.

Sob esse contexto atinente ao que é livre, fala-se em liberdade de iniciativa. $\mathrm{Na}$ vigente Constituição Federal de 1988, a livre iniciativa foi alçada à categoria de fundamento da ordem econômica ${ }^{2}$. Seus valores sociais fundamentam, aliás, toda a República³. Trata-se, destarte, de um elevado grau axiológico intrínseco a todo o arcabouço jurídico-pátrio, sendo sua observância impositiva às funções executiva, legislativa e jurisdicional do Estado.

Enquanto fundamento, pode-se considerar a livre iniciativa como causa, razão de ser da ordem econômica constitucional, ligando-se à sua finalidade - assegurar a todos uma existência digna, conforme os ditames da justiça social - por meio dos princípios, os pontos de partida para a efetivação dos comandos da Constituição Econômica ${ }^{4}$.

Desde suas primeiras prescrições normativas, a livre iniciativa guarda denotação econômica. No entanto, a pura e simples

2 Art. 170. A ordem econômica, fundada na valorização do trabalho humano e na livre iniciativa, tem por fim assegurar a todos existência digna, conforme os ditames da justiça social, observados os seguintes princípios:

(...). (Grifou-se).

3 Art. $1^{\circ}$ A República Federativa do Brasil, formada pela união indissolúvel dos Estados e Municípios e do Distrito Federal, constitui-se em Estado Democrático de Direito e tem como fundamentos: (...) IV - os valores sociais do trabalho e da livre iniciativa; (...). (Grifou-se).

4 Cf. Souza (1989, p. 31); Bastos e Martins (1990, p. 14-15). 
literalidade de seus vocábulos não traz a segurança necessária à definição de seu conteúdo, formado pelas liberdades de exercer empresa (empreendimento econômico), associação e contrato 5 .

Dito isso, convém debater, mormente ao cada vez mais crescente número de casos concretos $^{6}, a$ (in)constitucionalidade da medida que determina a intervenção em sociedades empresárias ${ }^{7}$ em conflito por meio de terceiros na

5 "Numa visão prática, podemos dizer claramente que a garantia de livre iniciativa como liberdade de empreendimento seria nula de sentido se houvesse restrições à liberdade de associação. Da mesma forma, eventual legislação que viesse a restringir mais severamente a liberdade contratual inviabilizaria por completo a livre iniciativa. Destaque-se que uma das mais importantes facetas da livre iniciativa encontra-se na liberdade de trabalho, em todas as suas formas. Daí a própria norma constitucional (art. 170, caput) colocar, lado a lado, a livre iniciativa e a valorização do trabalho humano como fundamentos da ordem econômica brasileira. (...)" (Abreu, 2008, p. 73-77), Cf., ainda, Bastos e Martins (1990, p. 16).

6 Cf. TJSP, AI 0257499-41.2012.8.26.0000, publicado em 21-5-2013; TJRS, AI 70048077184, publicado em 5-7-2012; TJMG, AC 3052506, publicada em 124-2000; TJPR, AC 7179966, julgada em 18-5-2011; TJMG, AI 10024122994379002, publicado em 14-42014; TJRS, AI 70059261958, publicado em 7-7-2014; TJRJ, AI 00680606920138190000, publicado em 10-4-2014; TJPR, AC 4111997, julgada em 31-10-2007; TJPR, AI 2861867, julgado em 12-5-2005; TJMG, AI 10702140479651001, publicado em 30-9-2014; TJRN, AI 137449, julgado em 26-4-2011; TJSE, EDl no AI 2005205076, julgado em 18-10-2005; TJRS, AI 70056511868, publicado em 4-11-2013; TJRO, MC 20000120000116646, julgada em 7-12-2004; TJPR, AI 5974769, julgado em 13-10-2009; TJSC, AI 20130829709, julgado em 30-6-2014; TJRN, AI 2011.000037-2, julgado em 17-5-2011; TJSP, AI 5968114900, publicado em 5-2-2009, entre inúmeros outros arestos.

7 Por razões jurimétricas, delimitou-se a sociedade limitada (LTDA) como objeto dos exemplos e análises vindouros. Primeiramente, porque os dados mais recentes do Departamento de Registro Empresarial e Integração (DREI) apontam que mais de 99,4\% das sociedades empresárias constituídas no qualidade de administradores judiciais provisórios. Em outras palavras, pretende-se verificar se esta tutela estatal está ou não autorizada pelo sistema jurídico posto, tendo-se, como parâmetro de validade constitucional, a liberdade de iniciativa. Mais que buscar e oferecer uma simples resposta, serão traçadas métricas de constitucionalidade calcadas em argumentos sediados na teoria dos direitos fundamentais e no direito societário.

Para tanto, inicialmente, o trabalho categoriza a liberdade de iniciativa como um direito fundamental. Em seguida, é traçado o panorama das citadas medidas judiciais nominativas. Mais que buscar e oferecer uma simples resposta, são traçadas métricas de constitucionalidade calcadas em argumentos sediados na teoria dos direitos fundamentais e no direito societário, as quais são justificadas com base na preservação de interesses sociais e extra-sociais.

\section{DIREITOS FUNDAMENTAIS E LIVRE INICIATIVA}

\subsection{Breves apontamentos sobre os direitos funda- mentais}

Como se infere do subtítulo, pretende-se, neste momento, fazer breves apontamentos sobre os direitos fundamentais. O destaque ao teor não analítico das próximas linhas tem sua razão de ser. Se, de um lado, é certo que a categorização da livre iniciativa enquanto direito fundamental, e a consequente consideração de suas

Brasil são LTDAs (http://www.dnrc.gov.br/Estatisticas/Caep0100.htm). Ademais, em estudo empírico paradigmático sobre o assunto, Marcelo Guedes Nunes (2010, p. 83-133) detectou que $83,33 \%$ das sociedades empresárias em conflitos dessa ordem são daquela natureza. 
hipóteses de restrição, são preciosos ao desenvolvimento do tema objeto desta investigação, de outro, investigações aprofundadas, vastas ou conteudistas sobre os direitos fundamentais traria um indisfarçável e malquerido desvio de foco - o que, de certa maneira, pode ser chamado de prejuizo - ao desenvolvimento proposto.

Ante tais observações, estabeleço como premissa conceitual de direitos fundamentais aquela formulada por Leonardo Martins e Dimitri Dimoulis, a qual os define como "direitos público-subjetivos de pessoas físicas ou jurídicas, contidos em dispositivos constitucionais - ou com força jurídica constitucional - e que, portanto, encerram caráter normativo supremo dentro do Estado, tendo como finalidade limitar o exercício do poder estatal em face da liberdade individual" ( Martins \& Dimoulis, 2012, p. 40).

Reputo o conceito moderno e consonante ao sistema jurídico brasileiro, mormente em face da adoção da concepção material (aberta) de direitos fundamentais pelo art. $5^{\circ}$, $\S 2^{\circ}$ e $3^{\circ 8}$, da Constituição Federal, que repudia eventuais formulações conceituais que se prestem a enxergar como funda-

8 Art. $5^{\circ}(\ldots)$.

$\oint 2^{\circ}$ - Os direitos e garantias expressos nesta Constituição não excluem outros decorrentes do regime e dos princípios por ela adotados, ou dos tratados internacionais em que a República Federativa do Brasil seja parte.

$\S 3^{\circ}$ Os tratados e convenções internacionais sobre direitos humanos que forem aprovados, em cada Casa do Congresso Nacional, em dois turnos, por três quintos dos votos dos respectivos membros, serão equivalentes às emendas constitucionais.

(...). Cf. Mendes e Branco (2014, p. 200); Sarlet, Marinoni e Mitidiero (2012, p. 267-272). mentais apenas os direitos inscritos no seu Título II (arts. $5^{\circ}$ a 17). Com efeito, nada impede o reconhecimento de direitos público-subjetivos que, embora estejam geograficamente posicionados fora do Título II da Constituição, são fundamentais. Nesse sentido, aliás, vem se posicionando o Supremo Tribunal Federal (STF) ${ }^{9}$.

9 Cf. Súmula Vinculante n. ${ }^{\circ} 25$; Ação Direta de Inconstitucionalidade n. 939/DF, publicada em 18-3-94; e Suspensão de Tutela Antecipada n. ${ }^{\circ} 175$, publicada em 25-9-2009. Na doutrina, Sarlet, Marinoni e Mitidiero expõem rol exemplificativo calcado em diversos estudos "(...) é possível elencar alguns exemplos de direitos fundamentais sediados em outras partes do texto constitucional, sem prejuízo de outros que poderiam ser incluídos na listagem: o direito de igual acesso aos cargos públicos (art. 37, I), os direitos de associação sindical e de greve dos servidores públicos (art. 37, VI e VII), assim como o direito dos servidores públicos à estabilidade no cargo (art. 41), que, ademais, constitui verdadeira garantia da cidadania. Poder-se-ia cogitar, ainda, da legitimação ativa para a iniciativa popular legislativa (art. 61, § $2^{\circ}$ ), que, agregado ao art. 14, III, pode ser considerado como autêntico direito de participação política. Da mesma forma ocorre com a garantia da publicidade e fundamentação das decisões judiciais (art. 93, IX), bem como as limitações constitucionais ao poder de tributar (art. 150, I a VI). No âmbito do direito à educação (art. $6^{\circ}$ e 205), é possível mencionar as dimensões mais específicas da liberdade de ensino e pesquisa (art. 206) e o direito subjetivo ao ensino público fundamental obrigatório e gratuito (art. 208, I), seguido da garantia do exercício dos direitos culturais (art. 215). Também o direito à proteção do meio ambiente (art. 225) já encontrou ampla acolhida na doutrina e jurisprudência brasileira. Ainda na esfera da ordem social, assumem relevo os exemplos da igualdade de direitos e obrigações entre os cônjuges (art. 226, §5 5), o direito dos filhos a tratamento igualitário e não discriminatório (art. 227, § $6^{\circ}$ ), o direito ao planejamento familiar incentivado pelo Estado (art. 226, $\S 7^{\circ}$ ), o direito à proteção da entidade familiar (art. 226), bem como o direito à proteção das crianças e dos adolescentes (art. 227)" (Sarlet, Marinoni \& Mitidiero, 2012, p. 282-283). Conquanto não se esteja, aqui, concordando com o caráter fundamental de todos os direitos supra-arrolados, é certo que, para cada um deles, há fortes argumentos nesse sentido, sempre amparados na concepção material. 
Classicamente, consagra-se a existência de quatro gerações ou dimensões de direitos fundamentais. A primeira abarca os direitos da liberdade, primeiros a constar nos instrumentos normativos constitucionais ocidentais, tendo por titular o indivíduo, que pode exercer a resistência e a oposição perante o Estado; a segunda envolve os direitos atinentes à igualdade, a saber, os sociais, culturais e econômicos, bem como os coletivos; a terceira alberga os consectários da fraternidade, quais sejam, o desenvolvimento, a paz, o meio ambiente, a propriedade sobre o patrimônio comum da humanidade e a comunicação; por fim, a quarta representa a globalização política, filiando-se aos ideais de democracia, informação e pluralismo ${ }^{10}$.

Os direitos fundamentais conferem aos seus titulares uma pretensão de adoção de comportamentos positivos, negativos ou de sujeição em face do Estado (eficácia vertical) ou dos próprios particulares (eficácia horizontal), fornecendo diretrizes vinculantes para a atuação do Poder Público - incluído, aqui, o Poder Judiciário"1. A estruturação jurídica dessa ideia remon-

10 Cf. Bonavides (2011, p. 562-571); Mendes e Branco (2014, p. 168); ainda, com visão crítica quanto às nomenclaturas, Martins e Dimoulis (2012, p. 20-24).

1 Cf. Holthe (2010, p. 348); "Os direitos fundamentais e sua especial garantia se propõem, a partir da tradição e do desenvolvimento histórico alemão, a prevenir ataques do Estado à esfera de existência individual (...). Ao sentido negativo ou de defesa se acrescenta uma significação positiva não menos importante: trata-se, também, de que a pessoa faça uso dessa liberdade. Só mediante uma tal atualização podem-se tornar realidade a autodeterminação do indivíduo e sua participação responsável na vida política, social, econômica e cultural e pode cobrar vida a ordenação de uma sociedade constituída em liberdade (...)" (Hesse, 2009, p. 32-22). ta à histórica ${ }^{12}$ teoria dos status, de Georg Jellinek (1912). Para o jurista alemão, identificam-se os seguintes status nos direitos fundamentais: (i) negativo, que exige do Estado uma esfera de atuação protetora de ingerências indevidas, garantindo-se a liberdade (Jellinek, 1912, p. 105-126) ${ }^{13}$; (ii) positivo, assegurando a utilização, pelos indivíduos, das instituições estatais para exigir prestações específicas, como os direitos sociais (Jellinek, 1912, p. 127-150) ${ }^{14}$; e (iii) ativo, pelo qual se permite ao cidadão a participação efetiva na formação da vontade estatal, v.g., exercendo direitos políticos (Jellinek, 1912, p. 151-212) ${ }^{15}$.

Embora não esteja alçado a grau de tópico em sua obra, Jellinek também apresenta o quarto status - o passivo (subiectiones) - ao

12 Cf. Pieroth e Schlink (2012, p. 51-54); Alexy (2008, p. 254-268); Mendes e Branco (2014, p. 187-188); Martins e Dimoulis (2012, p. 48-52); Holthe (2010, p. 348); Miranda (2000, p. 87-90).

$13 \mathrm{Cf}$. Hesse "(...) os direitos fundamentais impõem claramente a ação estatal nas condições expostas; regulam, pois, a questão do sim, do pressuposto dessa atuação (...)" (Hesse, 2009, p. 46); Pieroth e Schlink (2012, p. 51-52); Martins e Dimoulis (2012, p. 49-50); Alexy (2008, p. 258-262).

14 Pieroth e Schlink "Este é o estado em que o particular não pode ter a sua liberdade sem o Estado, mas em que depende de medidas do Estado para a criação e conservação da sua existência livre. Este estado encontra-se conformado e assegurado nos direitos fundamentais quando e na medida em que sejam direitos de reivindicação, de proteção, de participação, de prestação e de procedimento. (...) (Pieroth e Schlink, 2012, p. 52-53); Cf. Hesse (2009, p. 39); Alexy (2008, p. 263-267); Martins e Dimoulis (2012, p. 51).

15 Cf. Alexy "As posições do status ativo estão sempre ligadas às posições dos outros status, pois o exercício de uma competência é sempre obrigatório ou proibido (status passivo) ou facultativo (status passivo)" (Alexy, 2008, p. 269); Pieroth e Schlink (2012, p. 53-54); Hesse (2009, p. 38); Martins e Dimoulis (2012, p. 52). 
abordar as relações do indivíduo com o sistema de direito público. Nesse ponto, depreende-se que o indivíduo está subordinado aos poderes estatais, legitimandose contenções ao conteúdo e alcance dos direitos fundamentais, em benefício de outros titulares ${ }^{16}$.

\section{A temática desse trabalho atrai, particu- larmente, interesse sobre o status passivo, o qual possibilita amplas espécies de contenções aos direitos fundamentais, tais como restrições, limitações, condiciona- mentos, regulamentações, concretizações legis- lativas, auto-rupturas, deveres e suspensões ${ }^{17}$,}

16 "Per effetto della subordinazione allo Stato, che forma la base di ogni attività statale, l'individuo entro la sfera dei suoi doveri individuali, si trova nello status passivo (passiven Status), nello status sbiectionis, nel quale à esclusa l'autodeterminazione, e quindi la personalità. Uma personalità assoluta dell'individuo, non subordinata, in massima, in alcuna maneira ala volontà dello Stato è una cumaezione incompatibile con la natura dela Stato (...)" (Jellinek, 1912, p. 96-97); Cf. Alexy (2008, p. 256-257).

17 "A restrição tem que ver com o direito em si, com a sua extensão objectiva; o limite ao exercício de direitos contende com a sua manifestação, com o modo de se exteriorizar através da prática do seu titular. A restrição afecta certo direito (em geral ou quanto a certa categoria de pessoas ou situações), envolvendo a sua compressão ou, doutro prisma, a amputação de faculdades que a priori estariam nele compreendidas; o limite reporta-se a quaisquer direitos. A restrição funda-se em razões específicas; o limite decorre de razões ou condições de carácter geral, válidas para quaisquer direitos la moral, a ordem pública e o bem-estar numa sociedade democrática (...)]. O limite pode desembocar ou traduzir-se qualificadamente em condicionamento, ou seja, num requisito de natureza cautelar que se faz depender o exercício de algum direito, como a prescrição de um prazo (para o seu exercício), ou de participação previa (v.g., para realização de manifestações), ou de registro (para o reconhecimento da personalidade jurídica de associação), ou de conjugação com outros cidadãos num número mínimo (para a constituição de partidos), ou posse de documentos (por exemplo, passaportes), ou de sem que, com isso, possa se falar em extinção daqueles. Entre as hipóteses de

autorização vinculada (para a criação de escolas particulares e cooperativas). O condicionamento não reduz o âmbito do direito, apenas implica, umas vezes, uma disciplina ou uma limitação da margem de liberdade do seu exercício, outras vezes um ónus. Uma coisa é a regulamentação ou preenchimento ou desenvolvimento legislativo (ou, porventura, convencional) do conteúdo do direito; outra coisa a restrição ou diminuição ou compressão desse conteúdo. Uma coisa é regulamentar, por razões de certeza jurídica, de clarificação ou de delimitação de direitos; outra coisa é restringir com vistas a certos e determinados objetivos constitucionais. (...) Muito menos se confunde a restrição com a concretização legislativa, destinada a conferir, total ou parcialmente, exequibilidade a normas constitucionais não exequíveis por si mesmas. (...). Um quid é a auto-ruptura material ou edição de preceito constitucional geral e concreto ou, em certos casos, individual e concreto; outro a restrição, necessariamente contida em norma geral e abstracta. A auto-ruptura é uma excepção à regra constitucional geral (...); a restrição uma decorrência de certa regra ou de certo princípio em face de outra ou outro. E no domínio dos direitos, liberdades e garantias, a auto-ruptura ou quebra da Constituição apenas pode ocorrer, como se sabe, por força de normas constitucionais originárias, nunca por força de revisão constitucional. A restrição distingue-se do dever, pela sua completa falta de autonomia, por se situar no plano do conteúdo de certo direito e só fazer sentido por referência a ele. O dever é uma situação jurídica passiva, traduzido na imposição a alguém de agir ou não agir de alguma maneira; já a restrição se prende ao perfil específico de alguns direitos, ao modo como se apresentam na vida jurídica e à protecção que, assim vêm a receber. O dever (não fundamental) pode não constar da Constituição; a restrição tem sempre de nela se estear, imediata ou mediatamente. Finalmente, são diversos os conceitos de restrição e de suspensão. A restrição atinge um direito a título permanente, e sempre apenas parcialmente; a suspensão, provocada por situações de necessidade, atinge um direito a título transitório, equivale a um eclipse. A restrição apaga uma parcela potencial do direito; a suspensão paralisa ou impede, durante algum tempo, o seu exercício, no todo ou em parte (e, só neste caso acaba, por ventura, por corresponder a uma restrição)" (Miranda, 2000, p. 239-241). Contra, entendendo boa parte dessas espécies com sinônimos, Pieroth e Schlink (2012, p. 94). 
admissão dessas contenções, costumam ter destaque doutrinário ${ }^{18}$ : (i) quando o exercício do direito fundamental extrapola a sua área ou âmbito de proteção, v.g., o direito de associação para propósitos comerciais é livre, mas pode ser vedado diante de um objeto ilícito; e (ii) se o Estado, com ou sem prévia reserva legal, regulamenta um direito fundamental, v.g., dever dos administradores de sociedades limitadas de prestar contas e as formalidades de convocação de assembleias.

\subsection{Categorização da livre iniciativa enquanto direito fundamental}

Já se viu que a liberdade se apresenta como um direito fundamental de primeira dimensão, enquadrado na categoria do status negativo de Georg Jellinek, pelo qual se permite aos indivíduos a oposição diante das ingerências ilegítimas do Estado.

De fato, a liberdade de iniciativa é semelhante às demais asseguradas pela Constituição. No campo particular, pode ser exercida livremente dentro de seu âmbito de proteção, tal qual ocorre com as liberdades de locomoção, crença, sexual, imprensa e expressão. Trata-se do viés econômico do direito à liberdade. Por isso, as leis restritivas da liberdade de iniciativa econômica devem observar o seu conteúdo essencial, como um direito fundamental, funcionando como um limite negativo à atuação dos poderes estatais (Petter, 2008, p. 180).

18 Cf. Martins e Dimoulis (2012, p. 142-145); Hesse (2009, p. 51-53); Mendes e Branco (2014, p. 239-254); Sarlet, Marinoni e Mitidiero (2012, p. 327-348).
Anteriormente, se disse que a Constituição categorizou as liberdades de associação e ação profissional como direitos fundamentais. Ocorre que, muito embora as liberdades de empreender economicamente e de contrato - facetas subjacentes da livre iniciativa - não estejam taxativamente consignadas como direitos fundamentais, vige no Brasil a concepção material albergada pelo art. $5^{\circ}, \S 2^{\circ}$, da Lei Maior.

Ora, sendo livre o exercício de qualquer trabalho, ofício ou profissão, esse regime de liberdade abrange, também, o de empreender economicamente, o que só pode ser possível diante da possibilidade de exercício da autonomia de vontade mediante a formação de contratos ${ }^{19}$.

Tutela-se, nesse liame, a livre iniciativa, configurada como um direito público-subjetivo de pessoas físicas ou jurídicas que está expressamente contida em dispositivos constitucionais de força normativa suprema dentro do Estado, seja como fundamento da ordem econômica ${ }^{20}$, seja por suas facetas ${ }^{21}$, limitando o exercício do poder estatal em face da liberdade individual, só podendo ser restrita (status negativo) em hipóteses específicas, como a extrapolação de seu âmbito de proteção e a regulamentação estatal condizente ao seu conteúdo.

Trata-se, portanto, de direito fundamental.

\footnotetext{
19 Cf. Petter (2008, p. 180); Andrade (1986, p. 293-295).

$20 \mathrm{CF}$, art. 170, caput.

${ }^{21} \mathrm{CF}$, art. 50, XIII, XVII, XVIII e XX; art. 170, Parágrafo Único.
} 


\section{A CONSTITUCIONALIDADE ABSTRATA DA INTERVENCẼO JUDICIAL NOMINATIVA}

\subsection{Mapeamento do problema posto}

Diuturnamente, conflitos entre sócios e sócios-administradores de sociedades mercantis saem do plano real para o processual, abarrotando o Poder Judiciário com medidas ${ }^{22}$ visando à destituição liminar (ou cautelar) de algum sócio da gestão do empreendimento conjunto, em virtude de ações ou omissões que configurem falta grave aos deveres próprios ao encargo. Como a sociedade não pode ficar sem comando e representação, é comum que tais pleitos sejam cumulados com o pedido de nomeação de administradores ou interventores judiciais.

Os administradores judiciais são auxiliares da justiça provisoriamente designados para gerir, cogerir ou fiscalizar a gestão da sociedade em conflito. A finalidade precípua da nomeação desses interventores é a cooperação com o Poder Judiciário, no sentido de preservar o interesse social até que haja uma cognição posterior ou exauriente sobre o conflito levado à tutela estatal.

Contudo, a legislação brasileira é lacunosa no oferecimento de parâmetros ou autorizações para a intervenção judicial nominativa supracitada, gerando insegurança na concretização desta medida por parte dos tribunais. Em pesquisa paradigmática realizada sobre acórdãos

22 Geralmente, medidas cautelares preparatórias para procedimentos dissolutivos parciais e dissoluções parciais com pedidos cautelares incidentais ou de tutela antecipada. do Tribunal de Justiça do Estado de São Paulo (TJSP) com base na jurimetria, Marcelo Guedes Nunes (2010, p. 93-133) verificou que apenas $16,66 \%$ das decisões que se debruçaram sobre a nomeação de administradores judiciais tiveram motivação legal. Das demais, 8,33\% o fizeram com base doutrinária. Nenhum, com base jurisprudencial. Em paralelo, todas se referiram às necessidades práticas (fáticas) de um interventor provisório, para atenuar as consequências da quebra da affectio societatis, viabilizar a gestão ordinária ou verificar as acusações levadas à tutela jurisdicional. Nelas, os aplicadores do direito se limitaram a apresentar um raciocínio consequencialista, pelo qual os benefícios decorrentes da atuação do gestor externo nomeado pelo Poder Judiciário foram ressaltados (Nunes, 2010, p. 119).

Quando buscaram amparo na lei, os julgados analisados se limitaram a referências processuais, usualmente, o poder geral de cautela, hoje regulado pelo art. 297, caput ${ }^{23}$, do Código de Processo Civil (CPC), o qual autoriza o magistrado a determinar as medidas que considerar adequadas para efetivação da tutela provisória.

A questão é um tanto quanto mais complexa. Bem se sabe, há debates parlamentares atinentes à superveniência de

23 Correspondente, no diploma adjetivo civil recém-revogado, ao art. 798: "Além dos procedimentos cautelares específicos, que este Código regula no Capítulo II deste Livro, poderá o juiz determinar as medidas provisórias que julgar adequadas, quando houver fundado receio de que uma parte, antes do julgamento da lide, cause ao direito da outra lesão grave e de difícil reparação". 
um novo Código Comercial. Na Câmara dos Deputados, encontra-se em trâmite o Projeto de Lei (PL) n. ${ }^{\circ} 1.572 / 2011$; no Senado Federal, foi constituída, em maio de 2013, uma Comissão de Juristas para a elaboração de um anteprojeto, calcado naquele já existente perante a Câmara dos Deputados, com o fim de dar celeridade aos debates nas duas casas parlamentares. Em novembro de 2013, o dito objeto foi entregue ao Presidente do Senado Federal, convertendo-se no PL n. ${ }^{\circ}$ 487/2013. Em ambos os Projetos ${ }^{24}$, foram estatuídos microparâmetros para a administração judicial de sociedades em conflito corporativo. Contudo, a inconteste leniência parlamentar brasileira não permite fazer prognósticos acerca da eventual promulgação e vigência de um novo Código Comercial, de modo que se perquiri, nesse trabalho, apenas o direito posto.

Ocorre que, independentemente da superveniência de tais microparâmetros, deve-se, antes, perquirir a validade constitucional de intervenções dessa ordem. Em outras palavras, faz-se necessário averiguar se, diante do sistema constitucional brasileiro - que tem a liberdade de iniciativa como fundamento, causa e razão de ser da ordem econômica -, está abstratamente autorizada uma tutela jurisdicional que venha a ir de encontro aos atos constitutivos societários, suprimindo, ainda que provisoriamente, o exercício da gestão corporativa por administradores legitimamente instituídos via contrato.

24 Arts. 1.017 a 1.024 do PL n. ${ }^{\circ} 487 / 2013$ e art. 123 do PL n. ${ }^{\circ} 1.572 / 2011$.
Sendo a resposta negativa, isto é, vista como inconstitucional uma tutela dessa ordem, não apenas as intervenções calcadas no art. 297, caput, do CPC devem cessar, mas, também, as lastreadas em qualquer dispositivo legal autorizador que venha a ser eventualmente promulgado falo, aqui, das previstas nos Projetos do novo Código Comercial. Se a resposta for positiva, ou seja, vista a intervenção como constitucionalmente permitida, aí, então, poder-se-á estipular e investigar microparâmetros, haja vista o fundamento de validade superior.

\subsection{Livre iniciativa e interesse social como alicerces de justificação}

No Brasil, diferentemente do que ocorre em Portugal ${ }^{25}$ e na Espanha ${ }^{26}$, a intervenção do Estado na gestão das sociedades

\footnotetext{
25 Artigo $86^{\circ}$ (Empresas privadas) (...)
}

2. O Estado só pode intervir na gestão de empresas privadas a título transitório, nos casos expressamente previstos na lei e, em regra, mediante prévia decisão judicial.

Apesar do caráter genérico do preceito albergar, a nosso ver - embora não exclusivamente -, a intervenção judicial temporária visando a dirimir conflitos societários, esta não é a opinião de José Joaquim Gomes Canotilho e Vital Moreira (2007), para quem "(...) não entra no conceito de intervenção na gestão para efeito deste preceito a suspensão ou interdição ou inibição dos gestores de empresas privadas (ou quaisquer outras), por acto de autoridade pública (designadamente por via judicial, ou por decisão de autoridade reguladora, sob reserva de confirmaçãa judicial), em caso de infraç̧ão grave às normas que regem a vidas das empresas ou os mercados" (p. 1.016).

26 Artículo 128

(...)

2. Se reconoce la iniciativa pública en la actividad económica. Mediante ley se podrá reservar al sector público recursos o servicios esenciales, especialmente en caso de monopolio y asimismo acordar la intervención de empresas cuando así lo exigiere el interés general. 
empresárias não tem guarida constitucional explícita. Com efeito, a nomeação de administradores judiciais apresenta-se como uma das formas mais gravosas de intervenção judicial sobre o funcionamento das sociedades limitadas, convindo indagar a sua constitucionalidade ante aos parâmetros constitucionais subjacentes.

Bem se viu, as liberdades de contrato e de exercer empresa são facetas do direito fundamental à livre iniciativa, das quais decorre a franca opção, pelos sócios de uma sociedade limitada, do objeto, lugar, tempo e forma da organização mercantil. Consequentemente, é prerrogativa daqueles a escolha de quem exercerá a administração societária, o que será feito por meio do contrato social ou de ato em separado.

Baseada na livre iniciativa, a escolha dos administradores não é um ato permanente, facultando-se aos sócios a mudança na gestão societária. Omisso o contrato social, submetem-se os quotistas ao status passivo de sujeições estatais, tendo o legislador imposto dificuldades para o afastamento dos administradores. Quanto a estas, diferem de acordo com a existência ou inexistência de justa causa para a destituição.

Tratando-se de destituição imotivada, ela somente se opera pela aprovação de titulares de quotas correspondentes, no mínimo, a dois terços do capital social ${ }^{27}$.

27 Código Civil

Art. 1.063. O exercício do cargo de administrador cessa pela destituição, em qualquer tempo, do titular, ou pelo término do prazo se, fixado no contrato ou em ato separado, não houver recondução.
Se a assunção do encargo administrativo tiver se dado em ato separado ao contrato social, demanda-se a aprovação de mais da metade do capital social28.

A sistemática, embora clara, é de difícil concretização prática. Diz-se isso amparado em pesquisa jurimétrica realizada sobre dados da Junta Comercial do Estado de São Paulo, pela qual 98,34\% das sociedades limitadas não têm administrador profissional (Mattos Filho et al., 2014, p. 4). Nesse contexto, parece razoável esperar que a assunção do encargo administrativo se dê, na hercúlea maioria dos casos, por meio do contrato social, atraindo, assim, a necessidade de aprovação de dois terços do capital social. Entretanto, mais da metade das vezes, a sociedade simplesmente não tem um sócio controlador, havendo participações idênticas (fifty-fifty) em 44,91\% das sociedades limitadas (Mattos Filho et al., p. 5). Logo, seria impossível a destituição imotivada em sociedades assim constituídas, restando ao(s) descontente(s) a negociação visando a uma alteração amigável na gestão ou, ainda, o exercício do direito de (livre) retirada da associação mercantil.

$\S$ lo Tratando-se de sócio nomeado administrador no contrato, sua destituição somente se opera pela aprovação de titulares de quotas correspondentes, no mínimo, a dois terços do capital social, salvo disposição contratual diversa.

(...).

28 Art. 1.076. Ressalvado o disposto no art. $1.061 \mathrm{e}$ no $\S 1^{\circ}$ do art. 1.063, as deliberações dos sócios serão tomadas:

(...)

II - pelos votos correspondentes a mais de metade do capital social, nos casos previstos nos incisos II, III, IV e VIII do art. 1.071;

(...). 
Entretanto, há casos em que a manutenção do exercício da administração por qualquer um dos sócios ${ }^{29}$ se mostra, supervenientemente, contrária aos interesses sociais, prejudicando os propósitos lucrativos, o cumprimento do objeto social, a honra objetiva ou a conformidade jurídica da gestão societária. A contrariedade aos interesses sociais configura, a meu ver, justa causa para a destituição societária.

No Direito Comparado, o Código Comercial Francês ${ }^{30}$ e o Código Civil Português ${ }^{31}$

29 Se a administração for feita por terceiros, simplesmente não há interesse de agir em demandas judiciais interventivas.

30 Article L223-25. Le gérant peut être révoqué par décision des associés dans les conditions de l'article L. 223-29, à moins que les statuts prévoient une majorité plus forte. Si la révocation est décidée sans juste motif, elle peut donner lieu à des dommages et intérêts.

En outre, le gérant est révocable par les tribunaux pour cause légitime, à la demande de tout associé.

Par dérogation au premier alinéa, le gérant d'une société à responsabilité limitée exploitant une entreprise de presse au sens de l'article 2 de la loi ${ }^{\circ}$ 86-897 du ler août 1986 portant réforme du régime juridique de la presse n'est révocable que par une décision des associés représentant au moins les trois quarts du capital social." (Grifou-se).

31 Artigo 257.

( Destituição de gerentes)

\section{(...)}

2. O contrato de sociedade pode exigir para a deliberação de destituição uma maioria qualificada ou outros requisitos; se, porém, a destituição se fundar em justa causa, pode ser sempre deliberada por maioria simples.

3. A cláusula do contrato de sociedade que atribui a um sócio um direito especial à gerência não pode ser alterada sem consentimento do mesmo sócio. Podem, todavia, os sócios deliberar que a sociedade requeira a suspensão e destituição judicial do gerente por justa causa e designar para tanto um representante especial.

4. Existindo justa causa, pode qualquer sócio requerer a suspensão e a destituição do gerente, em acção intentada contra a sociedade. preveem a possibilidade de afastamento de administradores por justa causa. No Brasil, a destituição de administradores nessas condições não é explicitamente disciplinada pelos artigos codificados que tratam da sociedade limitada, exsurgindo, na omissão do contrato social ${ }^{32}$, o uso integrativo e analógico do arcabouço normativo atinente às sociedades simples ${ }^{33}$. Nesse sentido, o art. 1.019, caput $^{34}$, do Código Civil, estatui que a justa causa, reconhecida judicialmente a pedido de qualquer sócio, independentemente de sua participação societária, pode ser motivo para a destituição do quotista-administrador investido neste encargo por cláusula expressa do contrato social.

5. Se a sociedade tiver apenas dois sócios, a destituição da gerência com fundamento em justa causa só pelo tribunal pode ser decidida em acção intentada pelo outro.

6. Constituem justa causa de destituição, designadamente, a violação grave dos deveres do gerente e a sua incapacidade para o exercício normal das respectivas funções.

(..).

32 Art. 1.053. A sociedade limitada rege-se, nas omissões deste Capítulo, pelas normas da sociedade simples.

Parágrafo único. O contrato social poderá prever a regência supletiva da sociedade limitada pelas normas da sociedade anônima.

33 Com efeito, os dados da pesquisa de Mattos Filho (et al., 2014) revelam que $63,20 \%$ das sociedades limitadas são microempresas ou empresas de pequeno porte e quase $80 \%$ têm até $\mathrm{R} \$ 50.000,00$ (cinquenta mil reais) de capital social (p. 2). Ante à baixa expressão econômica, aliado ao caráter pessoa, é válido presumir que tais sociedades não costumam eleger o regime da LSA como norma supletiva.

34 Art. 1.019. São irrevogáveis os poderes do sócio investido na administração por cláusula expressa do contrato social, salvo justa causa, reconhecida judicialmente, a pedido de qualquer dos sócios. (..). 
Em regra, essa obrigatoriedade da tutela jurisdicional transfigura a relação entre os quotistas em uma batalha de acusações recíprocas, amparadas pela fragilidade do contrato social, e instruídas com documentos de procedência incerta, como recibos não timbrados, relatórios criados unilateralmente e menções à existência de graves violações, cujas provas - normalmente, perícias e testemunhas -, só serão produzidas na fase instrutória. Tal situação de conflito é incrementada em fifty-fifty companies, as quais correspondem, na antevista amostra, a 44,91\% das sociedades limitadas.

Com a busca da tutela jurisdicional, o conflito suprarrelatado costuma ${ }^{35}$ vir acompanhado de um pedido liminar de afastamento do quotista-administrador ou, havendo pluralidade desta condição, de um deles. A seu turno, é esperado que o consócio judicialmente atacado reconvenha com pedidos congêneres, pondo o julgador em uma severa celeuma decisória, mormente em face da comentada usual fragilidade das provas documentais.

Em situações como essa, em que falhas na gestão são certas, mas existe dúvida entre a posição da razão frente aos interesses contrapostos, muitos magistrados findam por nomear terceiros como administradores judiciais para gerir, temporariamente, sociedades em conflito corporativo.

35 Em análise jurimétrica de tais pedidos, Marcelo Guedes Nunes identificou que 44,87\% deles foram feitos em Ações de Dissolução Parcial por Exclusão; 33,33\% em Medidas Cautelares inominadas; 6,41\% em Ações de Dissolução Total; 5,13\% em Ações de Dissolução Parcial por Retirada e 10,26\% por outros meios processuais, v.g., ações indenizatórias (Nunes, 2010, p. 89-90).
Empiricamente, a nomeação de administradores externos para o exercício da gestão societária, pedida em $20,52 \%$ das demandas, tem deferimentos na metade delas em primeira instância, chegando a, aproximadamente, $80 \%$ em segundo grau de jurisdição (Nunes, 2010, p. 93-96).

A questão é, afinal, saber se tais intervenções na liberdade de iniciativa são constitucionalmente admitidas. Para responde-la, faz-se necessário verificar em que casos uma gestão societária - exercida por pessoas livremente estipuladas pelos consócios - não goza de proteção constitucional, ou seja, está fora do âmbito de proteção da liberdade de empreendimento econômico. Particularmente, convém perquirir se uma gestão juridicamente incorreta - um não-interesse social - pertence ou não ao âmbito de proteção da liberdade de empreendimento econômico.

A análise do âmbito de proteção de um direito fundamental contempla a verificação de restrições constitucionais ou de reservas de lei restritivas, ambas expressas $^{36}$. Conquanto a Lei Maior não preveja uma só linha de regras acerca da administração de sociedades mercantis, é certo, porém, que anteviu, explicitamente, a possibilidade de o legislador ordinário perfazer restrições legais à liberdade de empreendimento econômico, a teor do seu art. 170, Parágrafo Único, pelo qual é "assegurado a todos o livre exercício de qualquer atividade econômica, indepen-

36 Cf. Canotilho (2003, p. 1.275-1.277); Mendes e Branco (2014, p. 239); Martins e Dimoulis (2012, p. 129; Sarlet, Marinoni e Mitidiero (2012, p. 327-335); Pieroth e Schlink (2012, p. 97-98). 
dentemente de autorização de órgãos públicos, salvo nos casos previstos em lei".

Bem, a lei não tutela a gestão societária juridicamente incorreta. Ao contrário, o ordenamento infraconstitucional se cerca de preceitos que admitem a destituição e responsabilização daqueles que, quebrando o dever de fidúcia inerente à administração societária, descumprem normas legais e contratuais ${ }^{37}$. Assim, invariavelmente, uma gestão juridicamente incorreta está fora do âmbito de proteção da liberdade de empreendimento econômico.

Por esse ângulo, uma tutela jurisdicional que afaste um administrador violador de interesses sociais do exercício de sua função não pode ser considerada uma contenção à livre iniciativa, na medida em que uma gestão contrária àqueles está fora do âmbito de proteção deste direito fundamental.

Superada essa questão, segue carente de resposta a viabilidade constitucional de a tutela jurisdicional ser intrusiva a ponto de nomear um terceiro, ainda que temporariamente, para gestão da organização empresarial. Se, por um lado, o provimento judicial que substitui um quotista-administrador por um consócio parece se alinhar ao âmbito de proteção da livre iniciativa, por outro, a troca por alguém estranho ao ato constitutivo para o exercício da gestão empresarial faz exsurgir dúvidas sobre tal aderência, ainda que, em ambas as hipóteses, essas inter-

37 Em excesso de poderes, falha no dever de informação e violações ao duty of loyalty e ao duty of care. Para detalhes sobre as falhas e consequências de uma gestão juridicamente correta, Cf. Leite (2014, p. 231-249). venções estejam justificadas no interesse social a uma gestão juridicamente correta.

A objeção natural à segunda hipótese é a de que a inserção de um terceiro estranho ao capital social na administração do agente econômico violaria a liberdade de contrato, afinal, a praxe mercantil mostra que a maioria ${ }^{38}$ dos atos constitutivos não prevê a hipótese de intervenção judicial. Ocorre que, ao admiti-la, seria impossibilitada qualquer tutela interventiva dessa natureza, ainda que se nomeasse um par quotista, afinal, o contrato social só teria estipulado o então gestor - cujo afastamento se pretende - como administrador. Estar-se-ia, também aqui, afrontando a liberdade de contrato. Ora, a organização empresarial é composta por um feixe de contratos, contendo-se, neste, o pacto com o administrador. A condução de uma gestão juridicamente incorreta, ou seja, ilícita por violação à lei ou aos negócios jurídicos, é uma violação àquele contrato, contra a qual o requerente do afastamento nem sempre consegue se opor extrajudicialmente, seja pela insuficiência de seu capital social, seja pelo judiciar obrigatório previsto pelo Código Civil. A hipótese tratar-se-ia, assim, de preservação do âmbito de proteção da liberdade de contrato, uma vez que esta não contempla o desenvolvimento de objetos ilícitos - aludo, aqui, mais uma vez, ao objeto gestão, fruto de um dos contratos oriundos do feixe organizacional, qual seja, o entabulado com o administrador.

\footnotetext{
38 Em benefício da dúvida, não usei a expressão quase todos, embora nunca tenha visto um só que o fizesse.
} 
Mesmo assim, a nomeação de terceiros como gestores temporários se mantém estranhamente suspeita. A autorização ao exercício da administração por outro quotista permanece mais aceitável, provavelmente porque, embora o contrato social não preveja sua administração, ele compõe a estrutura de poder político da organização, de modo que sua participação no capital social lhe confere a possibilidade abstrata ${ }^{39}$ de exercer essa função.

De fato, o aparente maior conforto normativo na aceitação de uma solução, em detrimento de outra, se justifica. Contudo, já se viu que a administração judicial é um pedido feito em 20,52\% das demandas focadas no afastamento de administradores, mostrando-se comum que os legitimados ativos para pleitear medidas dessa natureza, simplesmente, não queiram ser incluídos ${ }^{40}$ na gestão. Nesse quadro, a conformação constitucional da nomeação de terceiros como administradores judiciais pode ser validamente aceita com base nos limites dos limites.

\subsection{Limites dos limites (schranken-schranken)}

Os chamados limites dos limites são decorrentes da Constituição, reportando-se, no que toca ao objeto desse estudo, à guarida de um núcleo essencial do direito fundamental (Mendes E Branco, 2014, p. 256). Em geral, o âmbito de proteção de um

39 Refiro-me, aqui, a um dos direitos decorrentes da perspectiva pessoal da quota societária. Nesse sentido, Cf. Carvalho de Mendonça (1945, p. 53-54).

40 Em uma das pesquisas empíricas que basearam esse trabalho, o índice de pedidos de assunção da função administrativa detectado foi de apenas 12,86\% sobre o total (Nunes, 2010, p. 93). direito fundamental é aferido mediante as contenções feitas pela Constituição e pela legislação ordinária, mormente quando há reserva legal. Ocorre que, diante desta reserva, indaga-se até que ponto poderia o legislador, abstratamente, restringir ou limitar direitos fundamentais. Esse ponto máximo (limite) da reserva legal (do limite), demarcaria o núcleo essencial do direito, isto é, aquele sobre o qual não pode haver progresso de contenções, sob pena de esvaziamento.

Esse limite do limite é explicado de diferentes maneiras pelas teorias batizadas de absoluta e relativa. Pela primeira, o núcleo essencial poderia ser definido de maneira autônoma e identificável. Para a segunda, a definição só pode ocorrer casuisticamente, após um processo de ponderação entre meios e fins, com base no princípio da proporcionalidade (Mendes \& Branco, 2014 , p. 258), ainda que nada reste do direito fundamental após o sopesamento (Alexy, 2008, p. 295-300). Adota-se, aqui, a proposta intermediária de Konrad Hesse $(1998)^{41}$, que admite o manejo casuístico do critério da proporcionalidade como

$41 \quad$ "(...) a proibição de limitações desproporcionais efetua também uma proteção absoluta do "núcleo essencial" dos direitos fundamentais, naturalmente, sob o pressuposto, que proporcionalidade seja entendida não só no sentido de uma mera perseguição de uma finalidade econômica, mas que a admissibilidade de tal perseguição de uma finalidade, exatamente, também seja aferida ao direito fundamental a ser limitado" (Hesse, K., 1998, p. 268). Mesmo ante essa junção de teorias, Hesse admite a possibilidade de casos excepcionais, onde quase mais nada pode restar de um direito, como a ordem de interdição de um louco perigoso em um estabelecimento psiquiátrico (tratando da liberdade). 
forma de identificação e proteção do próprio núcleo essencial.

Sobre a proporcionalidade da intervenção judicial nominativa de terceiros e a preservação do núcleo essencial da liberdade de iniciativa, então, serão tecidas as próximas linhas.

Entre os subcritérios da proporcionalidade, a adequação (conformidade) e a necessidade (exigibilidade) são, sem dúvidas, os de citação mais recorrente na doutrina ${ }^{42}$. Fala-se em adequação quando a medida adotada se revela apropriada à consecução do fim ao qual se destina ${ }^{43}$. Se o fim é proteger uma sociedade limitada dos prejuízos oriundos de uma gestão juridicamente incorreta, a intervenção judicial que, temporariamente, nomeie terceiros, auxiliares do juízo, para gerir o agente econômico, é meio indiscutivelmente apto para atingi-lo.

A necessidade, a seu turno, significa que não há outra situação, menos onerosa e igualmente adequada, que o Estado possa igualmente criar sem grande dispêndio. Verifica-se, então, se o fim pode ser alcançável por um meio igualmente eficaz, mas menos oneroso ${ }^{44}$. Esse subcritério é, certamente, o de mais valia na aferição das intervenções ora estudadas. Sendo possível nomear um quotista como administrador provisório - meio menos gravoso de intervenção -, não haverá proporcionalidade na medida que escolha um

42 Cf. Canotilho (2003, p. 269-270); Sarlet, Marinoni e Mitidiero (2012, p. 338-339); Martins e Dimoulis (2012, p. 194-208); Pieroth e Schlink (2012, p. 108112).

43 Por todos, Cf. Canotilho (2003, p. 269).

44 Por todos, Cf. Pieroth e Schlink (2012, p. 107-108). terceiro, estranho ao quadro societário, para exercer o dito encargo - meio mais gravoso de intervenção.

Paralelamente, já foram apresentados dados pelos quais $44,91 \%$ das sociedades limitadas são dúplices e fifty-fifty. O índice é, não por acaso, bastante próximo ao número de quotistas-padrão das sociedades em conflito: dois, em 43,59\% das amostras (Nunes, 2010, p. 91). Ante a grande probabilidade de dois únicos sócios-administradores se encontrarem envolvidos na contenda, mediante acusações recíprocas, a administração provisória por um terceiro pode vir a ser absolutamente necessária para a continuidade das relações mercantis e a preservação de todos os interesses sociais e extra-sociais que cercam a organização interventiva. Logo, não há como, a priori, descarta-la.

Admitida, em tese, a proporcionalidade da intervenção nominativa, é de se dizer que ela não atinge, definitivamente, $\mathrm{o}$ núcleo essencial da livre iniciativa. Isso porque se apresenta inconcebível falar em esvaziamento desse direito fundamental quando, mesmo ante a administração judicial por terceiros, (i) os sócios permanecem com seus poderes deliberativos, prerrogativas patrimoniais ${ }^{45}$ e pessoais ${ }^{46}$ e (ii) a organização seguirá formando e executando o seu feixe de contratos, bem como exercendo empresa. Assim, malgrado seja relevante, a intervenção do Estado, ainda que por meio de terceiros, não tem o condão de fazer minguar aquele direito fundamental.

\footnotetext{
${ }^{45}$ V.g., distribuição de lucros e resolução da quota.

46 V.g., direitos de fiscalização, informação, reunião, permanência ou retirada.
} 


\subsection{Interesses extra-sociais como alicerces de justificação}

Todo interesse que se encontra fora do espectro da sociedade e de sua estrutura de poder político é externo e, portanto, extra-social. Desse apontamento, sobressaem duas considerações. Primeiramente, não se pretende extirpar a proteção dos stakeholders em relação às decisões internas ou à atuação do agente econômico no mercado, tampouco menosprezá-la. Aqui, embora se reconheça a existência de tais interesses, os quais são conviventes com os sociais, atribuísse-os uma posição externa à corporação (Leite, 2015, p. 22).

\section{A Constituição se mostra pródiga em} elencar interesses extra-sociais. A começar, a valorização do trabalho é, tal qual a livre iniciativa, fundamento da ordem econômica, que, por sua vez, deve observar princípios como a soberania nacional, a defesa do consumidor, a redução das desigualdades sociais e a busca do pleno emprego ${ }^{47}$.

Sendo necessária a intervenção nominativa na gestão societária, tais interesses extra-sociais, constitucionalmente consagrados, tenderiam à autopreservação. A eventual derrocada da sociedade limitada, face a uma gestão juridicamente incorreta, não atingiria somente a sociedade e seus quotistas, mas repercutiria na comunidade com percalços imediatos na manutenção e geração de postos de trabalho. Outrossim, a regularidade da comercialização dos próprios serviços ou

47 Art. 170, I a IX. mercadorias que compõem o objeto da sociedade limitada, ou seja, sua permanência frente ao mercado relevante, é de importância constitucional, na medida da contribuição para um ambiente competitivo. Não por acaso, a livre concorrência é um dos princípios da ordem econômica.

Além disso, o funcionamento regular de uma sociedade limitada contribui com a arrecadação de tributos - interesse público secundário -, os quais possibilitam a realização dos objetivos fundamentais da República ${ }^{48}$, mediante, por exemplo, a realização de políticas públicas voltadas à saúde, educação, segurança e assistência social - interesses públicos primários inscritos ao longo da Carta Magna ${ }^{49}$.

Logo, também por esse viés abstrato, a intervenção judicial nominativa temporária configura-se como medida legítima e constitucional.

\section{CONSIDERAÇÕES FINAIS}

Nas linhas anteriores, verificou-se que a livre iniciativa se concretiza nas liber-

48 Constituição Federal, Art. $3^{\circ}$.

49 A despeito da indeterminação, deve-se compreender o interesse público como um somatório de interesses individuais coincidentes em torno de um bem da vida que lhes signifique um valor, proveito ou utilidade de ordem moral ou material. Os primários são o próprio fundamento do Estado, isto é, o oferecimento de justiça, segurança e bem-estar social. Os secundários, por sua vez, são aqueles que possibilitam a realização dos primários, representados, genericamente, pelos interesses do erário público (Borges, 2011, p. 10). Cf, ainda, o art. $6^{\circ}$, caput, da Lei Maior: "São direitos sociais a educação, a saúde, a alimentação, o trabalho, a moradia, o lazer, a segurança, a previdência social, a proteção à maternidade e à infância, a assistência aos desamparados, na forma desta Constituição". 
dades de empreender economicamente (exercer empresa), contrato, associação e ação profissional. Trata-se, sem dúvidas, de um direito fundamental no Estado Brasileiro, antevisto como o viés econômico do direito à liberdade.

Sendo uma expressão da livre iniciativa, a organização mercantil guarda interesses sociais representados pela busca do lucro, o cumprimento do objeto social, a honra objetiva, a superação de conflitos pelo princípio majoritário e a gestão juridicamente correta.

Logo, uma tutela jurisdicional que afaste um administrador violador de interesses sociais do exercício de sua função não pode ser considerada uma contenção à livre iniciativa, na medida em que a gestão contrária àqueles está fora do âmbito de proteção desse direito fundamental.

De certo, ainda que se dê com a nomeação de terceiros para a função de gestor mercantil, a intervenção judicial em conflitos societários preserva o núcleo essencial da livre iniciativa, bem como os interesses sociais e extra-sociais que circundam a organização empresarial. Com efeito, a eventual derrocada da sociedade, face a uma gestão juridicamente incorreta, não atingiria somente a sociedade e seus quotistas, mas repercutiria na comunidade com percalços imediatos na manutenção e geração de postos de trabalho.

Bem se sabe, o funcionamento regular do agente econômico contribui com a arrecadação de tributos - interesse público secundário -, os quais possibilitam a realização dos objetivos fundamentais da República, mediante, por exemplo, a realização de políticas públicas voltadas à saúde, educação, segurança e assistência social - interesses públicos primários inscritos ao longo da Carta Magna.

Pelo exposto, a intervenção judicial nominativa temporária configura-se, abstratamente, como medida legítima e constitucional, sendo imperioso que, casuisticamente, tal interferência seja justificada com base nas submedidas do critério da proporcionalidade, quais sejam, a adequação e a necessidade.

\section{REFERÊNCIAS}

Abreu, R. R. G. (2008). Livre iniciativa, livre concorrência e intervenção do estado no domínio econômico. Revista dos Tribunais, Vol. 97, (No. 874), pp. 70-100.

Alexy, R. (2008). Teoria dos direitos fundamentais. São Paulo: Malheiros.

Andrade, J. C. V. (1986). Os direitos fundamentais na constituição portuguesa de 1976. Lisboa: Estampa.

Bastos, C. R. E Martins, I. G. (1990). Comentários à Constituição do Brasil. (7 Vol.). São Paulo: Saraiva.

Black's Law Dictionary. (2009). (9a. Ed.). New York: West.

Bonavides, P. (2011). Curso de direito constitucional. (26a. Ed.). São Paulo: Malheiros.

Borges, A. G. (2011). Supremacia do interesse público: desconstrução ou reconstrução? Revista Eletrônica de Direito Administrativo, (n. 26), pp. 1-26.

Canotilho, J. J. G. (2003). Direito constitucional e teoria 
da constituição. (7a. Ed.). Coimbra: Almedina.

Canotilho, J. J. E Moreira, V. (2007). Constituição da República Portuguesa Anotada. (4a. Ed.). Coimbra: Coimbra Editora.

Carvalho De Mendonça, J. X. (1945) Tratado de direito comercial brasileiro. (3o Vol.). Rio de Janeiro: Freitas Bastos.

Dicionário Houaiss da Língua Portuguesa. (2009). Rio de Janeiro: Objetiva.

Grande Dicionário da Língua Portuguesa: E-N. (1972). São Paulo: LISA.

Grau, E. R. (2014). A ordem econômica na Constituição de 1988. (16a. Ed.). São Paulo: Malheiros.

Hesse, K. (1998). Elementos de direito constitucional da República Federal da Alemanha. Porto Alegre: Sergio Antonio Fabris Editor.

Hesse, K. (2009). Temas fundamentais do direito constitucional. São Paulo: Saraiva.

Holthe, L. (2010). Direito constitucional. (6a. Ed.). Salvador: Jus Podvim.

Jellinek, G. (1912). Sistema dei diritti pubblici subbiettivi. (2a. Ed.). Milano: Società Editrice Libraria.

Leite, M. L. (2014). A responsabilidade civil na administração judicial de sociedades limitadas - indenização em favor de sócios e da sociedade (parte 2). Revista de Direito Empresarial (RDEmp), Vol. 11, (No. 3), pp. 231249.

Leite, M. L. (2015). Morfologia do interesse social nas sociedades limitadas. Trabalho não publicado.

Martins, L. E Dimoulis, D. (2012). Teoria geral dos direitos fundamentais. (4. Ed.). São Paulo: Atlas.

Mattos, A. O., et al. (2014). Radiografia das sociedades limitadas. Núcleo de Estudos em Mercados e Investimentos da Fundação Getúlio Vargas. Recuperado el 17 de abril de 2015, de http://direitosp.fgv.br/nucleo-de-pesquisas/ nucleo-de-estudos-mercados-investimentos

Mendes, G. F. E Branco, P. G. (2014). Curso de Direito Constitucional. (9a Ed.) São Paulo: Saraiva.

Miranda, J. (2000). Manual de direito constitucional. (3a Ed.). (4o Vol.). Coimbra: Coimbra Editora.

Nunes, M. G. (2010). Cap. 9 Intervenção judicial liminar na administração de sociedades. En Poder de controle e outros temas de direito societário e mercado de capitais (pp. 83-133). São Paulo: Quartier Latin.

Petter, L. J. (2008). Princípios constitucionais da ordem econômica. (2a Ed). São Paulo: Revista dos Tribunais.

Pieroth, B. E Schlink, B. (2012). Direitos fundamentais. São Paulo: Saraiva.

Sarlet, I. W., Marinoni, L. G. E Mitidiero, D. (2012). Curso de direito constitucional. São Paulo: Revista dos Tribunais.

Silveira Neto, O. S. (2013). A livre concorrência e a livre iniciativa como instrumentos de promoção do desenvolvimento: a função estabilizadora da intervenção do Estado no domínio econômico. Revista de Direito Público da Economia, Vol. 11, (No. 42), pp. 123-140.

Souza, W. P. A. (1989). A experiência brasileira de constituição econômica. Revista de informação legislativa, Volumen 26, (No. 102), pp. 21-48. 
